\title{
Quantitative Vibrational Dynamics of Iron in Nitrosyl Porphyrins
}

\author{
Bogdan M. Leu, Marek Z. Zgierski, Graeme R. A. Wyllie, \\ W. Robert Scheidt, Wolfgang Sturhahn, E. Ercan Alp, \\ Stephen M. Durbin, J. Timothy Sage
}

\section{Supporting Information}

\section{A. Details of porphyrin synthesis}

General Information. All reactions and manipulations were carried out using standard Schlenkware techniques unless otherwise noted. Benzene was distilled over sodium and benzophenone. Nitric oxide was purchased from Specialty Gases and purified by passing through a trap containing $4 \AA$ molecular sieves immersed in an ethanol/dry ice slurry. This removes all higher oxides of nitrogen. ${ }^{1} \mathrm{Fe}_{2} \mathrm{O}_{3}$, (95\% enriched in ${ }^{57} \mathrm{Fe}$ ) was purchased from Cambridge Isotope Laboratories. $\mathrm{H}_{2}(\mathrm{OEP})$ was purchased from Midcentury Chemicals. $\mathrm{H}_{2}$ (DPIXDME), $\mathrm{H}_{2}$ (MPIXDME) and $\mathrm{H}_{2}$ (PPIXDME) were purchased from Porphyrin Products. $\mathrm{H}_{2}(\mathrm{TPP})$ was prepared according to the methods of Adler. ${ }^{2}$ The ferric chlorides, ${ }^{57} \mathrm{Fe}(\mathrm{Por})(\mathrm{Cl})$, were prepared using the metallation procedure described by Landergren and Baltzer. ${ }^{3}$

Synthesis and isolation of ${ }^{57} \mathrm{Fe} e^{\mathrm{II}}(\mathrm{OEP}) .{ }^{57} \mathrm{Fe}(\mathrm{OEP})(\mathrm{Cl})$ was converted to $\left[{ }^{57} \mathrm{Fe}(\mathrm{OEP})\right]_{2} \mathrm{O}$ by shaking with aqueous $\mathrm{NaOH}$ solution and drying over $\mathrm{MgSO}_{4} \cdot{ }^{4,5} 150 \mathrm{mg}$ of $\left[{ }^{57} \mathrm{Fe}(\mathrm{OEP})\right]_{2} \mathrm{O}$ was dissolved in benzene prior to several freeze/pump/thaw cycles. The reduction to four-coordinate ${ }^{57} \mathrm{Fe}^{\mathrm{II}}(\mathrm{OEP})$ was carried out according to Stolzenberg et al. ${ }^{6}$ by the cannula addition of $\sim 2.5$ $\mathrm{mL}$ of ethanethiol. The solution was stirred overnight prior to complete removal of all solvent under vacuum. This left the reddish solid ${ }^{57} \mathrm{Fe}^{\mathrm{II}}(\mathrm{OEP})$ coated to the sides of the Schlenk flask. This complex is extremely susceptible to oxidation and hence, never exposed to air in order to avoid re-oxidation to $\left[{ }^{57} \mathrm{Fe}(\mathrm{OEP})\right]_{2} \mathrm{O}$. The Schlenk flask was opened in a dry-box under a nitrogen atmosphere. The solid ${ }^{57} \mathrm{Fe}^{\mathrm{II}}(\mathrm{OEP})$ was loosened from the sides of Schlenk flask by gentle mechanical pressure with a spatula. A small portion of Apiezon M grease on the end of a second spatula was used to transfer the powder sample of ${ }^{57} \mathrm{Fe}^{\mathrm{II}}(\mathrm{OEP})$ to a glass slide where it 
was thoroughly mixed with the grease to form a concentrated homogenous mull which was loaded into the sample holder and transported and stored in a biological dry-shipper prior to the NRVS measurements. A small portion of the sample was also examined by Mössbauer spectroscopy at $4.2 \mathrm{~K}$ to confirm sample identity and purity. The values of the isomer shift $(0.68 \mathrm{~mm} / \mathrm{sec})$ and the quadrupole splitting $(1.64 \mathrm{~mm} / \mathrm{sec})$ agree with values reported previously. ${ }^{7}$

Synthesis of Polycrystalline ${ }^{57} \mathrm{Fe}(\mathrm{Por})(\mathrm{NO})$. Polycrystalline powder samples of the five ferrous (nitrosyl)porphyrin complexes, ${ }^{57} \mathrm{Fe}(\mathrm{Por})(\mathrm{NO})$ where Por = OEP, TPP, DPIXDME, MPIXDME and PPIXDME, were prepared in a similar manner to the reductive nitrosylation method described previously. ${ }^{8} 120 \mathrm{mg}$ of the ferric chloride ${ }^{57} \mathrm{Fe}(\mathrm{Por})(\mathrm{Cl})$ was dissolved in $5 \mathrm{~mL}$ of chloroform in a Schlenk flask. $0.5 \mathrm{~mL}$ of methanol and $0.1 \mathrm{~mL}$ of pyridine were added and the solution purged with argon. Nitric oxide was bubbled through the solution for approximately 5 minutes. The product was precipitated by addition of a large volume of methanol, isolated by filtration upon sintered glass and washed with several portions of methanol. The resulting polycrystalline samples were mixed with minimal Apiezon M grease and loaded into the sample holder. The identities and purity of the samples were confirmed by a combination of Mössbauer and IR spectroscopy.

${ }^{57} \mathrm{Fe}(\mathrm{TPP})(\mathrm{NO})$ Crystal Array. Single crystals of ${ }^{57} \mathrm{Fe}(\mathrm{TPP})(\mathrm{NO})$ were prepared by a modification of the above procedure. $25 \mathrm{mg}$ of ${ }^{57} \mathrm{Fe}(\mathrm{TPP})(\mathrm{Cl})$ was weighed in a $10 \mathrm{~mL}$ beaker which was placed in a crystallization jar, sealed with a 3-hole Twistit rubber stopper and evacuated and refilled with argon. $2.5 \mathrm{~mL}$ of chloroform, $0.5 \mathrm{~mL}$ of methanol and 2 drops of pyridine were added to the beaker whilst $2 \mathrm{~mL}$ of chloroform and $2.5 \mathrm{~mL}$ of methanol were added to the jar surrounding the beaker. Argon was bubbled through the jar by means of a 22 gauge needle, initially through the headspace then through the outer solution. The gas flow was changed to nitric oxide which was bubbled through both solutions for approximately 5 minutes. The jar was sealed and crystals were found to form after 2 weeks.

Since the individual crystals were too small to provide adequate signal, 25 crystals were arranged on the inner surface of a polystyrene sample cell in a $5 \times 5$ array. The unit cell of ${ }^{57} \mathrm{Fe}(\mathrm{TPP})(\mathrm{NO})$ contains a single molecular orientation with crystallographically required eightfold disorder of the bound NO. The crystals possessed a regular tetragonal bipyramidal morphology for which all molecules are arranged in a co-planar fashion coincident with the basal plane of the crystal. ${ }^{8}$ The crystals within the array were immobilized in a bed of Apiezon M grease and orientated such that the mean porphyrin plane lay parallel to the surface of the sample holder. NRVS data were collected in grazing incidence, with the X-ray beam $6^{\circ}$ from the 
face of the sample cell.

\section{B. FeNO kinetic energy distributions}

Tables 1-4 give the predicted kinetic energy distributions on the FeNO fragment. The fractional kinetic energies associated with motion of the Fe atom and the nitrosyl $\mathrm{N}$ and $\mathrm{O}$ atoms are equal to $e_{F e}^{2}, e_{N}^{2}$, and $e_{O}^{2}$, respectively. Only modes with at least $10 \%$ of kinetic energy localized on the FeNO fragment $\left(e_{F e}^{2}+e_{N}^{2}+e_{O}^{2}>0.1\right)$ are included. 


\section{References}

1. Dodd, R. E.; Robinson, P. L. Experimental Inorganic Chemistry; Elsevier: New York, 1957 p. 253.

2. Adler, A. D.; Longo, F. R.; Finarelli, J. D.; Goldmacher, J.; Assour, J.; Korsakoff, L. J. Org. Chem. 1967, 32, 476.

3. Landergren, M.; Baltzer, L. Inorg. Chem. 1990, 29, 556.

4. Fleischer, E. B.; Srivastava, T. S. J. Am. Chem. Soc. 1969, 91, 2403.

5. Hoffman, A. B.; Collins, D. M.; Day, V. W.; Fleischer, E. B.; Srivastava, T. S.; Hoard, J. L. J. Am. Chem. Soc. 1972, 94, 3620.

6. Stolzenberg, A. M.; Strauss, S. H.; Holm, R. H. J. Am. Chem. Soc. 1981, 103, 4763.

7. Dolphin, D.; Sams, J. R.; Tsin, T. B.; Wong, K. J. Am. Chem. Soc. 1976, 98, 6970.

8. Scheidt, W. R.; Frisse, M. E. J. Am. Chem. Soc. 1975, 97, 17-21. 
Table 1: Predicted FeNO kinetic energy distribution for B3LYP calculation on Fe(TPP)(NO).

\begin{tabular}{ccccc}
\hline \hline $\bar{\nu}\left(\mathrm{cm}^{-1}\right)$ & $e_{F e}^{2}$ & $e_{N}^{2}$ & $e_{O}^{2}$ & $e_{F e}^{2}+e_{N}^{2}+e_{O}^{2}$ \\
\hline \hline 1781 & 0.00 & 0.55 & 0.45 & 1.00 \\
476 & 0.10 & 0.00 & 0.00 & 0.10 \\
474 & 0.10 & 0.00 & 0.00 & 0.10 \\
386 & 0.39 & 0.35 & 0.23 & 0.97 \\
334 & 0.36 & 0.28 & 0.02 & 0.66 \\
318 & 0.21 & 0.01 & 0.00 & 0.22 \\
317 & 0.35 & 0.01 & 0.00 & 0.36 \\
308 & 0.26 & 0.16 & 0.01 & 0.43 \\
292 & 0.08 & 0.31 & 0.01 & 0.40 \\
268 & 0.03 & 0.11 & 0.05 & 0.19 \\
253 & 0.13 & 0.00 & 0.00 & 0.13 \\
216 & 0.05 & 0.12 & 0.08 & 0.25 \\
195 & 0.04 & 0.12 & 0.14 & 0.32 \\
186 & 0.02 & 0.50 & 0.02 & 0.54 \\
109 & 0.27 & 0.09 & 0.11 & 0.47 \\
77 & 0.01 & 0.06 & 0.59 & 0.66 \\
56 & 0.01 & 0.00 & 0.14 & 0.15 \\
44 & 0.00 & 0.04 & 0.19 & 0.23 \\
42 & 0.00 & 0.03 & 0.54 & 0.57 \\
27 & 0.07 & 0.02 & 0.03 & 0.12 \\
\hline \hline
\end{tabular}


Table 2: Predicted FeNO kinetic energy distribution for BP86 calculation on Fe(TPP)(NO).

\begin{tabular}{ccccc}
\hline \hline $\bar{\nu}\left(\mathrm{cm}^{-1}\right)$ & $e_{F e}^{2}$ & $e_{N}^{2}$ & $e_{O}^{2}$ & $e_{F e}^{2}+e_{N}^{2}+e_{O}^{2}$ \\
\hline \hline 1721 & 0.00 & 0.57 & 0.43 & 1.00 \\
623 & 0.27 & 0.49 & 0.19 & 0.95 \\
466 & 0.15 & 0.03 & 0.01 & 0.19 \\
461 & 0.10 & 0.01 & 0.00 & 0.11 \\
410 & 0.14 & 0.32 & 0.15 & 0.62 \\
333 & 0.24 & 0.40 & 0.01 & 0.65 \\
300 & 0.24 & 0.08 & 0.01 & 0.33 \\
280 & 0.06 & 0.09 & 0.09 & 0.24 \\
251 & 0.12 & 0.00 & 0.01 & 0.13 \\
236 & 0.14 & 0.03 & 0.03 & 0.20 \\
232 & 0.06 & 0.01 & 0.04 & 0.11 \\
195 & 0.03 & 0.35 & 0.02 & 0.40 \\
110 & 0.24 & 0.08 & 0.09 & 0.40 \\
88 & 0.01 & 0.09 & 0.55 & 0.65 \\
60 & 0.00 & 0.02 & 0.09 & 0.11 \\
44 & 0.00 & 0.01 & 0.35 & 0.36 \\
40 & 0.00 & 0.02 & 0.14 & 0.16 \\
37 & 0.00 & 0.03 & 0.41 & 0.44 \\
33 & 0.07 & 0.02 & 0.03 & 0.11 \\
\hline \hline
\end{tabular}


Table 3: Predicted FeNO kinetic energy distribution for B3LYP calculation on $\mathrm{Fe}(\mathrm{P})(\mathrm{NO})$.

\begin{tabular}{ccccc}
\hline \hline $\bar{\nu}\left(\mathrm{cm}^{-1}\right)$ & $e_{F e}^{2}$ & $e_{N}^{2}$ & $e_{O}^{2}$ & $e_{F e}^{2}+e_{N}^{2}+e_{O}^{2}$ \\
\hline 1718 & 0.00 & 0.56 & 0.44 & 1.00 \\
565 & 0.22 & 0.64 & 0.14 & 1.00 \\
444 & 0.05 & 0.04 & 0.03 & 0.12 \\
434 & 0.35 & 0.11 & 0.09 & 0.55 \\
417 & 0.26 & 0.01 & 0.00 & 0.27 \\
406 & 0.11 & 0.10 & 0.04 & 0.25 \\
354 & 0.01 & 0.06 & 0.08 & 0.15 \\
318 & 0.22 & 0.28 & 0.00 & 0.50 \\
292 & 0.50 & 0.04 & 0.01 & 0.55 \\
287 & 0.16 & 0.06 & 0.00 & 0.22 \\
282 & 0.17 & 0.05 & 0.00 & 0.22 \\
264 & 0.09 & 0.03 & 0.04 & 0.16 \\
248 & 0.06 & 0.07 & 0.17 & 0.30 \\
205 & 0.01 & 0.44 & 0.02 & 0.47 \\
103 & 0.27 & 0.08 & 0.09 & 0.44 \\
87 & 0.01 & 0.12 & 0.68 & 0.81 \\
49 & 0.00 & 0.00 & 0.11 & 0.11 \\
46 & 0.00 & 0.01 & 0.77 & 0.78 \\
\hline \hline
\end{tabular}


Table 4: Predicted FeNO kinetic energy distribution for B3LYP calculation on $[\mathrm{Fe}(\mathrm{TPP})(\mathrm{NO})]^{+}$.

\begin{tabular}{ccccc}
\hline \hline $\bar{\nu}\left(\mathrm{cm}^{-1}\right)$ & $e_{F e}^{2}$ & $e_{N}^{2}$ & $e_{O}^{2}$ & $e_{F e}^{2}+e_{N}^{2}+e_{O}^{2}$ \\
\hline 2001 & 0.00 & 0.61 & 0.38 & 0.99 \\
742 & 0.11 & 0.04 & 0.07 & 0.22 \\
729 & 0.31 & 0.15 & 0.29 & 0.75 \\
484 & 0.11 & 0.05 & 0.00 & 0.16 \\
481 & 0.12 & 0.08 & 0.01 & 0.21 \\
453 & 0.00 & 0.50 & 0.05 & 0.55 \\
451 & 0.00 & 0.51 & 0.05 & 0.56 \\
406 & 0.09 & 0.12 & 0.01 & 0.22 \\
403 & 0.04 & 0.10 & 0.01 & 0.15 \\
323 & 0.53 & 0.00 & 0.00 & 0.53 \\
314 & 0.31 & 0.03 & 0.01 & 0.35 \\
308 & 0.16 & 0.00 & 0.00 & 0.16 \\
305 & 0.08 & 0.04 & 0.06 & 0.18 \\
261 & 0.14 & 0.00 & 0.00 & 0.14 \\
249 & 0.14 & 0.02 & 0.01 & 0.17 \\
230 & 0.03 & 0.05 & 0.02 & 0.10 \\
224 & 0.05 & 0.08 & 0.02 & 0.15 \\
117 & 0.26 & 0.07 & 0.08 & 0.41 \\
73 & 0.00 & 0.05 & 0.65 & 0.70 \\
72 & 0.00 & 0.03 & 0.50 & 0.53 \\
53 & 0.01 & 0.05 & 0.26 & 0.32 \\
48 & 0.01 & 0.02 & 0.07 & 0.10 \\
\hline \hline
\end{tabular}

